\title{
Décadrages Décadrages
}

cinéma, à travers champs Cinéma, à travers champs

$13 \mid 2008$

Anna Sanders Films, cinéma et art contemporain

\section{Un amour de perdition}

\section{Raphaël Oesterlé}

\section{OpenEdition}

Journals

Édition électronique

URL : http://journals.openedition.org/decadrages/540

DOI : $10.4000 /$ decadrages. 540

ISSN : 2297-5977

\section{Éditeur}

Association Décadrages

\section{Édition imprimée}

Date de publication : 10 octobre 2008

Pagination : 118

ISBN : 978-2-9700582-8-1

ISSN : 2235-7823

Référence électronique

Raphaël Oesterlé, « Un amour de perdition », Décadrages [En ligne], 13 | 2008, mis en ligne le 10 octobre 2009, consulté le 22 septembre 2020. URL : http://journals.openedition.org/decadrages/540 ; DOI : https://doi.org/10.4000/decadrages.540

Ce document a été généré automatiquement le 22 septembre 2020.

(B) Décadrages 


\title{
Un amour de perdition
}

\author{
Raphaël Oesterlé
}

1 Plus connu pour son activité de chef opérateur aux côtés de Manoel de Oliveira ou de Joao César Monteiro ${ }^{1}$, Mário Barroso présentait en compétition son deuxième long métrage, après un interlude télévisuel (trois téléfilms tournés en 2005). Un amour de perdition se place sous un double patronage: celui du texte homonyme de Camilo Castelo Branco, classique de la littérature portugaise du XIX ${ }^{\mathrm{e}}$ siècle, et celui du film monumental qu'en a tiré Manoel de Oliveira, classique du cinéma portugais du $\mathrm{XX}^{\mathrm{e}}$ siècle. L'enjeu était donc de taille, d'autant plus que le réalisateur, connu pour son goût de la transgression technique, s'essayait ici au numérique.

2 Comment se situer devant ces références écrasantes? Barroso a choisi de prendre le contre-pied de la version oliveirienne. Alors que ce dernier avait privilégié une fidélité absolue au texte, le reprenant mot à mot pour livrer un film de plus de quatre heures, Barroso a conservé l'intrigue en la déplaçant à notre époque. Il la centre sur le personnage de Simão (Tomás Alves), adolescent anarchiste courant consciencieusement à sa perte, à la poursuite d'un amour d'emblée condamné. Il souligne par là le caractère atemporel de ces thèmes, comme en témoigne la fascination qu'exerce le livre de Castelo Branco sur le personnage principal. Celui-ci est montré le relisant obsessionnellement, captivé par ce reflet. Incapable de s'en détacher, il va rejouer pas à pas ce scénario originel.

3 Paradoxalement, cette actualisation (?) du récit accompagne un retour sur l'Histoire du Portugal. Sont soulevés en effet les fantômes des guerres coloniales, plaies ouvertes constitutives du Portugal contemporain. La génération adulte paraît toute entière modelée par ce passé indicible, engendrant des liens inextricables de dépendance ou de rancœur. Entre dette fondatrice et rédemption impossible, chacun parait encore en attente d'un verdict déjà prononcé. Seule l'idylle spontanée qui se noue sur la tard entre la jeune sœur de Simão et son ami d'enfance capverdien semble annonciatrice d'une possible réconciliation.

4 Une lumière solaire les accompagne d'ailleurs tout au long du film, venant contraster avec les intérieurs sombres de la maison familiale. Relevons ici que le passage au numérique n'a en rien édulcoré le style de Barroso, celui-ci se plaisant à aller toujours 
aussi loin dans le sombre ou le lumineux, et accordant à chacun des personnages ou des lieux de l'action une lumière propre.

5 Ce film de facture classique (dans le bon sens du terme) permet donc à Mário Barroso de dépasser son statut de technicien virtuose. Reste à espérer qu'il bénéficiera de l'attention qu'il mérite, à défaut d'une sortie helvétique.

Un amour de perdition (Um amor de perdição, Portugal, 2008, 81').

Réalisation : Mário Barroso.

Scénario : Carlos Saboga.

Image : Mário Barroso.

Montage : Francisco Garcia da Silva, Rui Mouráo.

Son : Pedro Melo.

Musique : Bernardo Sassetti.

Interprètes : Tomás Alves, Rui Morisson, Ana Padráo,...

\section{NOTES}

1. Collaboration sur laquelle il s'était exprimé lors d'un entretien publié dans le Décadrages $\mathrm{n}^{\circ} 10$, consacré à la Trilogie de Dieu, pp. 62-67. 